\title{
Biliary Diseases in Heart Transplanted Patients: A Comparison Between Cyclosporine A versus Tacrolimus-Based IMMUNOSUPPRESSION
}

\author{
J. Stief ${ }^{1}$, H. U. Stempfle ${ }^{1}$, M. Götzberger ${ }^{2}$, P. Überfuhr ${ }^{3}$, M. Köpple ${ }^{\circ}$, P. Lehnert ${ }^{2 *}$, C. Kaiser ${ }^{2}$, \\ U. Schiemann ${ }^{2}$ \\ ${ }^{1}$ Department of Cardiology, ${ }^{2}$ Department of Gastroenterology, ${ }^{3}$ Department of Cardiac Surgery, \\ University Hospital Munich (LMU), Germany
}

\begin{abstract}
A cyclosporine (CsA)-based immunosuppression is associated with an increased incidence of cholelithiasis after heart transplantation. It is not known if tacrolimus (Tac) has comparable biliary side effects in humans.

We evaluated the incidence of gallbladder sludge and cholelithiasis under Tac-based immunosuppression by ultrasound examinations in 31 cardiac transplants ( 25 male, 6 female, mean age: $59 \pm 11$ years). Data were compared to 57 patients $(47$ male, $10 \mathrm{fe}$ male, mean age: $58 \pm 11$ years) who received CsAbased immunosuppression.

6 patients receiving Tac and 6 patients receiving CsA had already gallstones prior to transplantation so that finally 25 patients of the Tac group and 51 patients of the CsA group could be evaluated.

In the Tac group the incidence of biliary sludge was $4 \%$ ( 1 of 25 ), of gallstones $28 \%$ (7 of 25 ). In comparison, patients receiving CsA developed biliary sludge in also 4\% (2 of 51) and gallstones in 25\% (13 of 51). Nine of 42 males in the CsA group (21\%) and eight of 20 males in the Tac group $(40 \%)$ developed either gallstones or sludge (n.s). Six of nine females in the CsA group $(67 \%)$, but none of five females in the Tac group $(0 \%)$ developed either gallstones or sludge $(\mathrm{p}=$ $0.01)$.

In summary, the incidence of biliary disease in patients with Tac is comparable with CsA-based immunosuppression. We recommend regular sonographical examinations to detect biliary diseases as early as possible. In cases of clinically, laboratory and sonographical signs of cholecystitis cholecystectomy is indicated. It seems that towards lithogenicity female patients benefit more from a Tac-based treatment because the occurrence of gallstones is rare.
\end{abstract}

\section{INTRODUCTION}

Cyclosporine A (CsA), a calcineurin phosphatase inhibitor is a widely used immunosuppressive agent after heart transplantation (HTx). CsA is metabolized in the liver and excreted predominantly via biliary secre-

\footnotetext{
$\circ$ Part of doctoral thesis, * In memoriam
}

tion, which results in an impaired biliary excretion of bile salts and therefore in cholestasis. In heart transplants a high incidence of cholelithiasis is observed in up to $35 \%$ of the patients [1]. The specific mechanisms for lithogenesis using CsA treatment have not been definitively elucidated, but various pathophysiological mechanisms have been discussed. Previous studies revealed an inhibition of ATP-dependent export carriers for bile salts, especially taurocholate and cysteinyl leukotriens in the hepatocyte canalicular membrane shown in liver plasma membrane vesicles of rats [2] as well as of humans [3]. Another study in rats has shown a decreased bile salt synthesis and secretion combined with an unchanged cholesterol secretion, which leads to an elevated cholesterol saturation of bile and consequently in gallstones [4]. However, Chanussot and co-workers found only a transient intrahepatic cholestasis in rats [5]. Galan and coworkers described an altering in liver plasma membrane composition, fluidity and function, as well as an induction of oxidative stress and depletion of hepatic glutathione and proteins, which might cause cholestasis [6].

It is not known if tacrolimus (Tac), a new calcineurin phosphatase inhibitor which improved the results of organ transplantation [7] has comparable biliary side effects like CsA in heart transplanted patients. The metabolism of Tac is similar to CsA, both drugs bind to immunophilins, afterwards the active receptor-drug-complex inhibits the enzyme calcineurin phosphatase [8]. Only a few studies exist in humans beyond potential cholestatic effects of Tac. Cao and co-workers stated that Tac may be warranted to prevent biliary morbidity based on a case report of a young liver transplanted patient. In a rat model, Mizuta and co-workers showed cholestatic effects of CsA including reduced bile flow and bile acid secretion, whereas Tac increased bile secretion with little influence on bile flow. Due to data of a later study they suggested that Tac in high doses might induce cholestasis by inhibiting bile acid secretion relatively $[9,10]$. Furthermore Tac applied in high doses induced cholestasis by inhibiting the biliary glutathione secretion [11].

The aim of this study was to evaluate the incidence and possible risk factors of gallbladder sludge and 
cholelithiasis in heart transplanted recipients treated with Tac- versus CsA-based immunosuppressive treatment. Further we studied the incidence of symptomatic cholelithiasis and the outcome of patients which required surgery.

\section{METHODS}

\section{PATIENTS}

31 heart transplant recipients ( 25 male, 6 female, mean age $59 \pm 11$ years, mean follow up $5 \pm 2.5$ years) with Tac-based immunosuppressive therapy were compared with 57 heart transplant recipients (47 male, 10 female, mean age $58 \pm 11$ years, mean follow up $11 \pm 4.6$ years) with a CsA-based immunosuppression. These both groups came from two different transplantation eras, the CsA group from 1985 to 2000, and the Tac group from 1993 to 2001. Patients were not randomized to one of these groups. The definite follow-up investigation was performed five years after transplantation, respectively. Body mass index (BMI), age, hyperlipidaemia, diabetes mellitus as well as laboratory parameters of liver-condition were also analysed to detect other risk factors of biliary disease. Patients with recurrent colics localized in the upper right-sided abdominal quadrant were considered as symptomatic.

\section{ABDOMINAL UltrasonOGRAPHY}

Ultrasonography was performed prior to transplantation and annually after transplantation using a 3.5 MHZ convex-array scanner (Siemens Sonoline Elegra, Erlangen, Germany) to detect biliary disease. The gallbladder was examined in intercostal and subcostal scans. Intraluminal findings were characterized as sludge (echogenic sedimentation) or gallstones (hyperechogenic reflexes with posterior acoustical shadow).

\section{Biochemical Analyses}

Blood samples were taken at 2-3 week intervals for determination of Tac and CsA blood levels. Initially the CsA level acquired by monoclonal monospecific im- munoassay, amounted to $160-180 \mathrm{ng} / \mathrm{ml}$. After 6 months the CsA dosage could be reduced to reach serum levels between 100-120 ng/ml. The corticosteroid dosage amounted initially to $7.5 \mathrm{mg} / \mathrm{die}$ and had been lowered over a period of 1-2 years to 5 $\mathrm{mg} /$ die. In addition to corticosteroids, combination therapy included a purinanalogon [either azathioprine (AZA 50-75 mg/die), or mycophenolate mofetil (MMF: serum levels in the first $1 / 2$ year $2.0-4.5 \mu \mathrm{g} / \mathrm{ml}$, later 1.5-3 $\mu \mathrm{g} / \mathrm{ml})$ ]. Since 1993 a Tac-based immunosuppressive therapy was introduced instead of a CsAbased treatment. The Tac level investigated by radioimmuno assay (RIA) amounted $12-16 \mathrm{ng} / \mathrm{ml}$ in the first 6- months after HTx, later 8-10 ng/ml. The MMF level in this combination accounted $1.5-3 \mu \mathrm{g} / \mathrm{ml}$.

Other laboratory measurements included serum glutamic pyruvate transaminase (SGPT), serum glutamic oxaloacetic transaminase (SGOT), $\gamma$-glutamyl transferase $(\gamma-G T)$, alcaline phosphatase (AP) and total serum bilirubine as markers of hepatotoxicity (Hitachi 917 Boehringer, Mannheim, Germany).

\section{STATISTICAL ANALYSES}

All data were expressed as mean \pm SD. Statistics were computed using Student's t-test for normally distributed data and Whitney-Mann $U$ tests for non-normally distributed data. For all tests, a two-tailed P value of less than 0.05 was considered significant. Statistical analyses were performed using SigmaStat 3.0 for Windows 2000. The ethical review board of the LudwigMaximilians University Munich approved the study. Written informed consent for participation was obtained from all subjects.

\section{RESULTS}

Table 1 shows the baseline demographic and blood chemical characteristics of 76 heart transplanted patients divided in those receiving tacrolimus $(n=25)$ and those receiving cyclosporin A $(\mathrm{n}=51)$. There was no significant difference between the study groups with regard to age, BMI, SGOT, SGPT, AP, $\gamma$-GT and

Table 1. Demographic characteristics and laboratory parameters of 76 heart transplanted patients divided in two groups receiving either tacrolimus or cyclosporin A as basic immunosuppressive drug.

\begin{tabular}{cccc}
\hline & $\begin{array}{c}\text { Tacrolimus } \\
\mathrm{n}=25\end{array}$ & $\begin{array}{c}\text { Cyclosporin A } \\
\mathrm{n}=51\end{array}$ & $\begin{array}{c}\text { Significance } \\
\text { (p-value) }\end{array}$ \\
\hline Age & $57 \pm 11.5$ & $57 \pm 10.8$ & n.s. \\
Male/female (n) & $20 / 5$ & $42 / 9$ & n.s. \\
BMI & $26.0 \pm 4.3$ & $27.3 \pm 7.2$ & n.s. \\
SGOT $(<40 \mathrm{U} / \mathrm{l})$ & $21.7 \pm 7.9$ & $21.3 \pm 8.5$ & n.s. \\
SGPT $(<45 \mathrm{U} / \mathrm{l})$ & $18.4 \pm 8.0$ & $17.1 \pm 8.4$ & n.s \\
AP $(<135 \mathrm{U} / \mathrm{l})$ & $73.7 \pm 15.5$ & $87.7 \pm 25.6$ & n.s \\
g-GT $(<55 \mathrm{U} / \mathrm{l})$ & $42.3 \pm 40.3$ & $49.7 \pm 45.1$ & n.s \\
Bilirubine $(<1.0 \mathrm{mg} / \mathrm{dl})$ & $0.67 \pm 0.29$ & $0.88 \pm 0.54$ & n.s \\
Diabetes mellitus (n) & 8 & 8 & n.s \\
Hyperlipidaemia (n) & 11 & 34 & n.s \\
\hline
\end{tabular}

BMI: body mass index, SGOT: serum glutamec oxalacetic transaminase, SGPT: serum glutamic pyruvate transaminase, g-GT: gglutamyl transferase 
Table 2. Incidence of gallstones/sludge in 76 heart transplanted patients divided in two groups receiving either tacrolimus or cyclosporin A as immunosuppression

\begin{tabular}{cccc}
\hline & $\begin{array}{c}\text { Tacrolimus } \\
\mathrm{n}=25\end{array}$ & $\begin{array}{c}\text { Cyclosporin A } \\
\mathrm{n}=51\end{array}$ & $\begin{array}{c}\text { Significance } \\
\text { Tac vs. CsA } \\
\text { (p-value) }\end{array}$ \\
\hline Male/female (n) & $20 / 5$ & $42 / 9$ & \\
Gallstones (\%) & $7(28)$ & $13(25)$ & n.s \\
Sludge (\%) & $1(4)$ & $2(4)$ & n.s. \\
Males with either & $8(40)$ & $9(21)$ & n.s. \\
gallst. or sludge (\%) & $0(0)$ & $6(67)$ & 0.01 \\
$\begin{array}{l}\text { Females with either } \\
\text { gallst. or sludge (\%) }\end{array}$ & 1 & 2 & n.s. \\
Surgery & 0 & 0 & n.s. \\
\hline
\end{tabular}

bilirubine as well as prevalence of diabetes and hyperlipidaemia.

6 patients $(19 \%)$ receiving Tac and 6 patients $(10 \%)$ receiving CsA had already gallstones prior to transplantation so that finally 25 patients of the Tac group and 51 patients of the CsA group could be evaluated for the incidence of biliary diseases for at least five years after cardiac transplantation (Table 2).

The annual serial abdominal ultrasound examination after HTx showed an gallstone- incidence in 13 patients under CsA treatment $(25 \%)$ and in seven patients under Tac treatment (28\%). Sludge was detected in two patients receiving $\mathrm{CsA}$ and in one patient receiving Tac (4\%, respectively).

Regarding gender, nine of the CsA treated male patients $(21 \%)$ had either gallstones or sludge compared to eight male patients in the Tac group (40\%). Among female patients six developed gallstones or sludge in the CsA group (67\%), but none in the Tac group (0\%), which was significantly different $(p=0.01)$.

Cholecystectomy was performed in two symptomatic patients receiving CsA (4\%) and in one patient treated with Tac $(4 \%)$. All symptomatic patients were operated via laparoscopic cholecystectomy. Complications were not seen in this population after surgery and hospitalization time was not elongated.

\section{Discussion}

Although there are numerous data about the lithogenic characteristics of a CsA-based immunosuppressive therapy in animal studies [2, 4-6, 12-14], as well as in transplanted patients $[1,15]$, clinical studies of hepatobiliary complications using Tac, which is similarly metabolized like CsA, are rare. Most animal model studies showed no or only mild lithogenic effects of Tac compared with CsA $[16,17]$. In contrast, Kawamura and co-workers showed even a significant increase in bile flow under Tac, whereas CsA treatment resulted in a significant decrease of bile flow in rats [18].

Our study revealed overall a high incidence of cholelithiasis in heart-transplanted patients with up to $28 \%$ compared with healthy persons which is somewhat higher than in other studies [19, 20], but in accordance to prevalence data of our own study on kid- ney/pancreas-transplanted type 1 (insulin-dependent) diabetic patients [21]. Among these heart-transplanted patients the incidence of cholelithiasis or sludge between Tac- versus CsA-based immunosuppressive treatment was nearly the same. Obviously, the findings of previous animal studies do not lead to clinically relevant different effects in humans.

All relevant laboratory analyses were similar in both groups and also in normal ranges.

Interestingly, some gender-depending observations were obvious. Under a Tac-based treatment, gallstones or sludge occurred exclusively in male patients, whereas in none of the female patients which was a signicicant difference. In contrast, under a CsA-based therapy percentually more female patients developed gallstones or sludge than male patients (67 vs. $21 \%$ ). So far we have no explantation for this finding.

Only a minority of our patients with gallstones became symptomatic and required surgery (6\% CsA, 4\% Tac). All affected transplanted patients underwent laparoscopical surgery without any complications like sepsis or peritonitis so that no prolonged hospitalizations were necessary. No cholecystitis was missed. Several studies described a high postoperative complication rate in cases of acute cholecystitis in transplanted patients with the suggestion to perform prophylactic laparoscopic cholecystectomy prior to or post transplantation in patients with gallstones [15, 22-24]. However, Steck and co-workers described only a minority of symptomatic heart transplanted patients with cholelithiasis which is the basis of our conservative procedure [25].

We conclude that due to the lithogenic effects of CsA and Tac serial abdominal ultrasonography of the gallbladder and regular controls of biochemical parameters of cholestasis are important to be aware of potential biliary complications. In cases of clinically, laboratory and sonographical signs of cholecystitis cholecystectomy is indicated. It seems that towards the lithogenicity female patients benefit more from a Tacbased treatment because the occurrence of gallstones is rare.

Acknowledgement: This study was supported by grants of the Friedrich-Baur-Stiftung (Munich). 


\section{REFERENCES}

1. Spes C.H., Angermann C.E., Beyer R.W., Schreiner J., Lehnert P., Kemkes B.M., Theisen K. Increased incidence of cholelithiasis in heart transplant recipients receiving cyclosporine therapy. J Heart Transplant 1990 Jul;Vol.9(4): 404-407

2. Boehme M, Muller M, Leier I, Jedlitschky G, Keppler D. Cholestasis caused by inhibition of the adenosine triphosphate-dependent bile salt transport in rat liver. Gastroenterology 1994;107:255-265

3. Kadmon M., Klünemann C., Böhme M., Ishikawa T., Gorgas K., Otto G., Herfahrt C., Keppler D. Inhibition by cyclosporine A of Adenosin Triphosphate-dependent transport from the hepatozyte into bile. Gastroenterology 1993; 104:1507-1514

4. Chan F.K.1., Zhang Y., Lee S.S., Shaffer E.A. The effects of liver transplantation and cyclosporine on bile formation and lipid composition: an experimental study in the rat. J Hepatol 1998;28:329-336

5. Chanussot F., Botta-Friedlund D., Lechene de la Porte P., Sbarra V., Portugal H., Pauli A.M., Hauton J., Gauthier A., Lafont $\mathrm{H}$. Effects of cyclosporine and corticosteroids on bile secretion in the rat. Transplantation 1992 Aug; 54(2):226-231

6. Galan A.I., Munoz M.E., Jiminez R. S-Adenosylmethionine protects against cyclosporine A-induced alterations in rat liver plasma membrane fluidity and functions. J Pharmacol Exp Ther 1999 Aug;290(2):774-781

7. Vincenti F, Jensik SC, Filo RS, Miller J, Pirsch J. A longterm comparison of tacrolimus (TAC) and cyclosporine in kidney transplantation: evidence for improved allograft survival at five years. Transplantation 2002 27;73:775-782

8. Jørgensen K.A., Koefoed-Nielsen P.B., Karamperis N. Calcineurin phosphatase activity and immunosuppression. A review on the role of calcineurin phosphatase activity and the immunosuppressive effect of cyclosporine A and tacrolimus. Scand J Immunol 2003 57;93-98

9. Mizuta K., Kobayashi E., Uchida H., Fujimura A., Kawarasaki H., Hashizume K. Influence of tacrolimus on bile acid and lipid composition in continuously drained bile using a rat model. Transpl Int 1999 12:316-322

10. Mizuta K., Kobayashi E., Uchida H., Hishikawa S., Kawarasaki $H$. Increase of bile acid production by tacrolimus in the rat liver. Transplant Proc 2003 35:437438

11. Sanchez-Campos S., Lopez-Acebo R., Gonzalez P., Culebras J.M., Tunon M.J., Gonzalez-Gallego J. Cholestasis and alterations of glutathione metabolism induced by tacrolimus (TAC) in the rat. Transplantation 1998 Jul 15; 66(1):84-88

12. Roman I.D., Fernandez-Moreno M.D., Fueyo J.A., Roma M.G., Coleman R. Cyclosporine A induced internalisation of the bile salt export pump in isolated rat hepatocyte couplets. Toxicol Sci 2003 71;276-281

13. Le Thai B., Dumont M., Michel A., Erlinger S., Houssin D. Cholestatic effect of cyclosporine in the rat. An inhibition of bile acid secretion. Transplantation 1988 Oct; 46(4):510-512

14. Yasumiba S., Tazuma S., Ochi H., Chayama K., Kajiyama G. Cyclosporin A reduces canalicular membrane fluidity and regulates transporter function in rats. Biochem J 2001 354:591-596
15. Milas M., Ricketts R.R., Amerson J.R., Kanter K. Management of biliary tract stones in heart transplant patients. Ann Surg 1996 Jun;223(6):747-753

16. Deters M., Klabunde T., Kirchner G., Resch K., Kaever V. Sirolimus/cyclosporine/tacrolimus interactions on bile flow and biliary excretion of immunosuppressants in a subchronic bile fistula rat model. Br J Pharmacol 2002 136:604-612.

17. Deters M., Nolte K., Kirchner G., Resch K., Kaever V. Comperative study analyzing effects of sirolimus-cyclosporine and sirolimus-tacrolimus combinations on bile flow in the rat. Dig Dis Sci 2001 Oct;46(10):2120-2126

18. Kawamura I., Takeshita S., Fushimi M., Mabuchi M., Seki J., Goto T. Induction of choleresis by immunosuppressant TAC through stimulation of insulin-like growth factor-I production in the liver of rats. Eur J Pharmacol 2001 419:99-105

19. Cao S, Cox K, So SS, Berquist W, Lee SP, Haigh WG, Concepcion W, Monge H, Esquivel CO. Potential effect of cyclosporine A in formation of cholesterol gallstones in pediatric liver transplant recipients. Dig Dis Sci 1997; 42:1409-1415

20. Ericzon B.G., Eusufzai S., Soderdahl G., Duraj F., Einarsson K., Angelin B. Secretion and composition of bile after human liver transplantation: studies on the effects of cyclosporine and tacrolimus. Transplantation 1997 Jan. 15;63(1):74-80

21. Schiemann U., Ferhat A., Götzberger M., Kaiser C., Stief J., Landgraf R., Dieterle C. Prevalence of cholecystolithiasis and its management among kidney/pancreas-transplanted type 1 (insulin-dependent) diabetic patients. Eur J Med Res 2008;13(3):127-30.

22. Menegaux F., Huraux C., Jordi-Galais P., Dorent R., Ghossoub J.J., Pavie A., Gandjjbakhch I., Chigot J.P. Cholelithiasis in heart transplant patients. Ann Chir. 2000 Nov;125(9):832-837

23. Graham S.M., Flowers J.L., Schweitzer E., Bartlett S.T., Imbembo A.L. The utility of prophylactic laparoscopic cholecystectomy in transplant candidates. Am J Surg 1995 Jan:169:44-49

24. Richardson W.S., Surowiec W.J., Carter K.M., Howell T.P., Mehra M.R., Bowen J.C. Gallstone disease in heart transplant recipients. Ann Surg 2003 273(2):273-276

25. Steck T.B., Costanzo-Nordin M.R., Keshavarzian A. Prevalence and management of cholelithiasis in heart transplant patients. J Heart Lung Transplant. 1991 NovDez;10(6):1029-1032

Received: January 19, 2009 / Accepted: January 26, 2009

Adress for correspondence:

PD Dr. med. Uwe Schiemann

Klinik und Poliklinik für Allgemeine Innere Medizin

Inselspital Bern

Freiburgstrasse

3010 Bern

Tel.: $0041(0)$ 31- 6322525

E-mail: uwe.schiemann@insel.ch 